INFLAMMATORY BOWEL DISEASE

\title{
Expression and localisation of matrix metalloproteinases and their natural inhibitors in fistulae of patients with Crohn's disease
}

\author{
T Kirkegaard, A Hansen, E Bruun, J Brynskov
}

Gut 2004;53:701-709. doi: 10.1136/gut.2003.017442

See end of article for authors' affiliations

Correspondence to:

Dr J Brynskov, Department of Medical

Gastroenterology C Herlev University Hospital, 75 Herlev Ringrej, DK-2730 Herlev, Copenhagen, Denmark brynskov@dadlnet.dk

Accepted for publication 28 October 2003

\begin{abstract}
Background: Fistulae are a troublesome complication of Crohn's disease but little is known of the final effector molecules responsible for matrix degradation. Although matrix metalloproteinases (MMPs) have been strongly implicated in tissue injury in Crohn's disease, their role in fistula formation is unknown. Aim: To determine the expression pattern of MMPs and tissue inhibitors of metalloproteinases (TIMPs) in fistulae of patients with Crohn's disease.

Patients and methods: Resected fistula specimens were obtained from patients with Crohn's disease $(n=11)$ and classified according to the predominant histological features - that is, acute versus chronic inflammation. Patients with fistulae due to other diseases $(n=9)$ and normal colon $(n=5)$ served as controls. MMP and TIMP protein expression was measured by single or double labelled immunohistochemistry, and mRNA expression by in situ hybridisation. MMP activity was measured by gelatin zymography.

Results: Compared with normal colon, strong MMP-3 expression was consistently observed in fistulae in Crohn's disease, irrespective of the stage of inflammatory activity. MMP-3 transcripts and protein were localised in large mononuclear cells and fibroblasts. MMP-9 transcripts and protein were expressed in granulocytes and only in fistulae with acute inflammation. Staining for MMP-1 and MMP-7 was weak and negative for MMP-10, whereas MMP-2 was equally expressed in normal colon and fistulae. TIMP-1, TIMP-2, and TIMP-3 expression was low in all samples. Similar expression patterns were found in fistulae of the disease control group. Fistulae also expressed active MMP-2 and MMP-9, as measured by gelatin zymography.

Conclusion: MMP-3 and MMP-9 are markedly upregulated in intestinal fistulae and may contribute to fistula formation through degradation of the extracellular matrix, irrespective of the underlying disease process.
\end{abstract}

$F$ istulae develop in approximately one third of patients with Crohn's disease and may result in severe distressing symptoms. ${ }^{1}$ Although the introduction of anti-tumour necrosis factor (TNF) $\alpha$ antibodies has offered an important advance in the treatment of fistulising Crohn's disease, ${ }^{2}{ }^{3}$ the management of this complication remains a major therapeutic challenge. Fistulae may occur in Crohn's disease as complications of surgery or abscess formation but more often they develop spontaneously as a result of active luminal disease. ${ }^{4}$ While infection, ischaemia, and malnutrition are important factors that contribute to postoperative fistula formation, ${ }^{4}$ the effect of immunosuppressants, most notably anti-TNF- $\alpha$ antibodies, suggests that immune mediated mechanisms also play a primary role in spontaneous fistula formation. ${ }^{2}$ Here they are thought to arise in a caviating ulcer or transmural fissure that gradually penetrate the surrounding soft tissue and eventually communicate with other bowel segments or organs or open on the skin..$^{5}$ Despite substantial progress in the understanding of the immune pathogenesis of inflammatory bowel disease (IBD), ${ }^{6}$ as well as the molecular genetics underlying distinct Crohn's disease phenotypes, ${ }^{78}$ little is known of the exact mechanisms responsible for fistula formation.

Proteinases, including serine proteinases and the large family of zinc dependent matrix metalloproteinases (MMP), mediate degradation of essentially all components of the extracellular matrix. ${ }^{9-11}$ While serine proteinase activity seems to be of minor importance for proteolytic tissue damage in the gut, ${ }^{12}{ }^{13}$ several lines of evidence strongly suggest that increased synthesis and release of certain MMPs, most notably MMP-3, play an important role as final mediators of immune mediated tissue injury in Crohn's disease. ${ }^{12-20}$ This has most clearly been demonstrated in an ex vivo human fetal gut model for human $\mathrm{IBD}^{21}$ in which addition of recombinant MMP-3 (stromelysin-1) caused extensive tissue injury. Moreover, tissue destruction induced by activation of resident lamina propria $\mathrm{T}$ cells was almost completely abolished by addition of a synthetic MMP inhibitor. ${ }^{21}$ MMP activity is regulated by specific tissue inhibitors of metalloproteinases (TIMPs) which are secreted by the same cell types that produce MMPs. ${ }^{9}{ }^{10}$

As no previous study has specifically addressed a role of these proteinases and their inhibitors in fistula formation, we examined the expression pattern of MMP-1, MMP-2, MMP-3, MMP-7, MMP-9, MMP-10, TIMP-1, TIMP-2, and TIMP-3 in Crohn's disease fistula specimens using immunohistochemistry and in situ hybridisation. For comparison, specimens obtained from a broad range of patients with fistulae due to causes other than Crohn's disease were also studied.

Abbreviations: bp, base pair; EDTA, ethylenediamine tetra acetic acid $I B D$, inflammatory bowel disease; MMP, matrix metalloproteinase; PBS, phosphate buffered saline; PFA, paraformaldehyde; RNase, ribonuclease; TNF- $\alpha$, tumour necrosis factor $\alpha$; TIMP, tissue inhibitor of metalloproteinase; TBS, Tris buffered saline 


\begin{tabular}{|c|c|c|c|}
\hline \multirow[b]{2}{*}{ Patient No } & \multirow[b]{2}{*}{ Disease site } & \multicolumn{2}{|l|}{ Fistula } \\
\hline & & Type & Localisation \\
\hline 1 & Rectum & External & Rectocutaneous \\
\hline 2 & Anal canal & External & Perianal \\
\hline 3 & Anus & External & Perianal \\
\hline 4 & lleum & Internal & Enterocolic \\
\hline 5 & lleoanal pouch & External & Perianal \\
\hline 6 & lleum & Internal & Enteroenteric \\
\hline 7 & lleum & External & Enterocutaneous \\
\hline 8 & Pelvic floor & External & Perianal \\
\hline 9 & Anus & External & Perianal \\
\hline 10 & Colon & External & Perianal \\
\hline 11 & Anorectum & External & Perianal \\
\hline \multicolumn{4}{|c|}{ Zymographic studies } \\
\hline 12 & Anal canal & External & Perianal \\
\hline 13 & Anal canal & External & Perianal \\
\hline 14 & Anal canal & External & Perianal \\
\hline 15 & Anal canal & External & Perianal \\
\hline
\end{tabular}

\section{MATERIALS AND METHODS Patients}

Fistula specimens were obtained by surgical excision in 11 patients with Crohn's disease diagnosed according to standardised diagnostic criteria. ${ }^{22}$ Eight women and three men (median age 31 years (range 16-57)) were studied. Six patients had macroscopic signs of active disease at the time of study. Further clinical details and type of fistulae are summarised in table 1 . One patient received topical treatment with 5-aminosalicylic acid enema ( $1 \mathrm{~g} /$ day), one oral prednisolone (7.5 mg/day), and one azathioprine (100 mg/day). One patient had received a single course of infliximab treatment $(5 \mathrm{mg} / \mathrm{kg})$ six days prior to surgery. Fistula specimens were also obtained from nine patients undergoing surgical treatment for fistulae due to causes other than Crohn's disease. This disease control group comprised three women and six men (median age 49 years (range 30-80)). Further clinical details and type of fistulae are summarised in table 2. None of these patients received immunosuppressive or anti-inflammatory treatment at the time of study. Finally, large bowel resection specimens of macroscopically normal colon were obtained from five patients (two men and three women; median age 49 years (range 27-68)) with no known history of IBD. For zymography experiments, fistulae from an additional four patients with Crohn's disease (median age 35 years (range 24-39)) (table 1) and four patients without Crohn's disease (median age 35 years (range 24-39)) (table 2) were obtained. The study was approved by the Regional Ethics Committee for Copenhagen County Hospitals.

\section{Tissues}

Fistula or normal colon specimens were immediately fixed in $4 \%$ paraformaldehyde (PFA) in phosphate buffered saline (PBS), dehydrated, and embedded in paraffin. Sample sections $(5 \mu \mathrm{m})$ were stained with haematoxylin and eosin and classified as either acute inflammation with granulation tissue, chronic inflammation with fibrosis, or a combination, according to standardised histological criteria. ${ }^{23}{ }^{24}$ Crohn's disease fistula specimens comprised four samples with prominent acute inflammation and granulation tissue, four samples with chronic inflammation and fibrosis, and three samples where both stages of inflammation were present. The disease control group comprised two samples with acute inflammation, three samples with chronic inflammation and fibrosis, and four samples with both features represented. Occasionally, a sample with an intact fistula tract was obtained in both groups.

\section{Single and double labelled immunohistochemistry}

Monoclonal and polyclonal antibodies against MMPs and TIMPs were purchased from Biogenesis (UK; MMP-1), NeoMarker (California, USA; MMP-2 (CA-4001), MMP-7 (ID2), MMP-9 (IIA5), MMP-10 (IVC5), TIMP-2, and TIMP3), Santa Cruz Biotechnology (UK; MMP-3 (sc-6930)), and Oncogene (UK; TIMP-1). Antibodies against CD68 (a macrophage marker) and vimentin (a fibroblast marker) were purchased from DakoCytomation (Denmark). Sections of formalin fixed and paraffin embedded tissue samples $(5 \mu \mathrm{m})$ were dewaxed in toluene for 10 minutes and thoroughly hydrated through series of diluted ethanol. After inhibition of endogenous peroxidase by $0.45 \%$ hydrogen peroxide in ethanol for 30 minutes, tissue sections were subjected to an antigen retrieval step by microwave oven treatment for 15 minutes in $10 \mathrm{mM}$ citrate buffer, pH 6.0 (MMP-2, MMP-9, and TIMP-3) or in $10 \mathrm{mM}$ Tris, $0.25 \mathrm{mM}$ ethylenediamine tetra acetic acid (EDTA), pH 9.0 (MMP-1, MMP-3, MMP-7, MMP-10, TIMP-1, and TIMP-2). In MMP-3 immunohistochemical experiments, non-specific reactions with endogenous biotin were blocked using a biotin blocking system (DakoCytomation). Other non-specific reactions were blocked with $0.5 \%$ casein in Tris buffered saline (TBS: $0.05 \mathrm{M}$ Tris/HCl, pH 7.6, 0.15 M NaCl). Primary antibodies against MMP-1 $(10 \mu \mathrm{g} / \mathrm{ml})$, MMP-2 $(1 \mu \mathrm{g} / \mathrm{ml}), \operatorname{MMP}-3(2 \mu \mathrm{g} / \mathrm{ml})$, MMP-7 (12 $\mu \mathrm{g} / \mathrm{ml})$, MMP-9 $(2 \mu \mathrm{g} / \mathrm{ml})$, MMP-10 $(2 \mu \mathrm{g} / \mathrm{ml})$, TIMP-1 $(5 \mu \mathrm{g} / \mathrm{ml})$, TIMP-2 $(0.1 \mu \mathrm{g} / \mathrm{ml})$, and TIMP-3 $(0.3 \mu \mathrm{g} /$ $\mathrm{ml}$ ) were applied for $12-20$ hours at $4^{\circ} \mathrm{C}$. Biotinylated rabbitantigoat immunoglobulin (Vector laboratories, California, USA), diluted 1:300 in $0.5 \%$ casein in TBS, was applied as a secondary antibody on sections incubated with the antibody against MMP-3. Avidin DH and biotinylated horseradish peroxidase $\mathrm{H}$ reagents (ABC) (Vector Laboratories, California, USA) was applied and the reactions visualised using 3,3'diaminobenzidine as a chromogen. For the remaining antibodies (MMP-1, MMP-2, MMP-7, MMP-9, MMP-10, TIMP-1, TIMP-2, and TIMP-3), the Envision Detection Kit (DakoCytomation) was used according to the manufacturer's instructions. Nuclei were stained with haematoxylin in all sections. The specificity of the immunohistochemical analysis (negative control) was confirmed by substituting the primary antibody with unspecific goat (MMP-3), rabbit (MMP-1, TIMP-2, and TIMP-3), or mouse (MMP-2, MMP-7, MMP-9, MMP-10, TIMP-1) immunoglobulins (DakoCytomation) on parallel sections. As positive control tissue, human placenta villous tissue from first trimester (MMP-2, MMP-3, MMP-7, and MMP-10, TIMP-1, TIMP-2, and TIMP-3) or colon with active ulcerative colitis (MMP-1, MMP-9) was used. Staining 


\begin{tabular}{|c|c|c|c|}
\hline \multirow[b]{2}{*}{ Patient No } & \multirow[b]{2}{*}{ Disease } & \multicolumn{2}{|l|}{ Fistula } \\
\hline & & Type & Localisation \\
\hline 1 & Appendiceal abscess & Internal & Appendicovesical \\
\hline 2 & Diverticular disease & External & Enterocutaneous \\
\hline 3 & Perianal abscess & External & Perianal \\
\hline 4 & Anal cancer & External & Enterocutaneous \\
\hline 5 & Ileal abscess & Internal & \|leum \\
\hline 6 & Natal abscess & External & Perianal \\
\hline 7 & Natal abscess & External & Perianal \\
\hline 8 & Haemorrhoids & External & Perianal \\
\hline 9 & Natal abscess & External & Perianal \\
\hline \multicolumn{4}{|c|}{ Zymographic studies } \\
\hline 10 & Congenital anal atresia & External & Retrovaginal \\
\hline 11 & Anal canal anastomosis & External & Perianal \\
\hline 12 & Natal abscess & External & Perianal \\
\hline 13 & Ileal abscess & External & Enterocutaneous \\
\hline
\end{tabular}

results were evaluated as either positive cellular staining (above background staining) or negative. Tissue sections were examined by light microscopy to determine the cellular localisation of immunohistochemical staining. Quantification was performed by counting the numbers of positive cells/ $\mathrm{mm}^{2}$ in a minimum of seven randomly chosen microscopic fields at a magnification of $25 \times$, as previously described. ${ }^{25} 26$

Representative samples were double stained with either CD68 (1:100) or vimentin (1:700) and MMP-2 or MMP-3. MMP-2 or MMP-3 stainings were visualised using 3-amino9-ethylcarbazole (Sigma-Aldrich, Denmark) as a chromogen whereas CD68 and vimentin stainings were visualised using Fast Blue BB (Sigma-Aldrich).

\section{Preparation of RNA probes}

cDNA fragments of human MMP-2 (base pair (bp) 2021 to 2296), MMP-3 (bp 1529 to 1757), and MMP-9 (bp 2009 to 2245) were obtained by reverse transcription-polymerase chain reaction on extracted total RNA from two cytokine stimulated transformed human colonic epithelial cell lines, HT-29 or DLD-1. Fragments were subcloned into pCR II-TOPO plasmid (Invitrogen, UK) and sequenced. The resulting constructs were linearised with Not I or Spe I restriction endonucleases (New England BioLabs, UK) before transcription with Sp6 or T7 RNA polymerase (New England
BioLabs), respectively, for two hours at $40^{\circ} \mathrm{C}$ ( Sp6) or $37^{\circ} \mathrm{C}$ (T7). Depending on the direction of the individual fragments, this produces either sense or antisense RNA probes. In vitro transcribed RNA was labelled with $\alpha\left[{ }^{33} \mathrm{P}\right]$ UTP (Amersham Biosciences, Denmark), according to the manufacturer's instructions. The DNA template was removed by adding $2 \mathrm{U}$ ribonuclease (RNase) free DNase (RQ1; Promega, Madison, Wisconsin, USA) for 15 minutes, and all enzyme activity was inhibited by adding $2 \mu$ EDTA $(0.2 \mathrm{M})$ prior to incubation for 10 minutes at $65^{\circ} \mathrm{C}$. After removing unbound $\alpha$ $\left[{ }^{33}\right.$ P]UTP using G50 spin columns (Amersham Biosciences), samples were extracted with phenol-chloroform-isoamyl alcohol (25:24:1) followed by re-extraction with chloroform-isoamyl alcohol (24:1). Yeast transfer RNA (40 $\mu \mathrm{g}$; Gibco BRL, UK) was added as a carrier protein and transcribed RNA was precipitated with ammonium sulphate and ethanol and dissolved in $20 \mu$ d diethylpyrocarbonate $\mathrm{H}_{2} \mathrm{O}$.

\section{In situ hybridisation}

Sections of formalin fixed and paraffin embedded tissue samples $(5 \mu \mathrm{m})$ were dewaxed in toluene for 10 minutes and thoroughly hydrated through series of diluted ethanol. All samples were treated with proteinase $\mathrm{K}(5 \mu \mathrm{g} / \mathrm{ml}$; Roche, Denmark) for 30 minutes at $37^{\circ} \mathrm{C}$ and prefixed in $4 \%$ PFA in PBS for 20 minutes at room temperature. To reduce
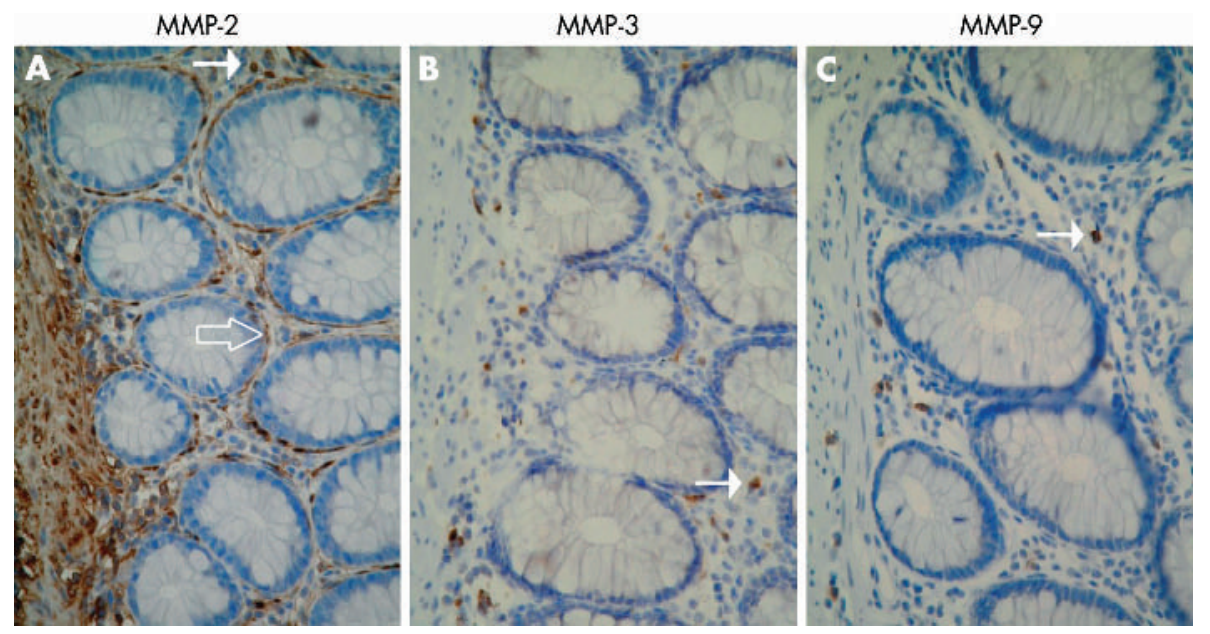

Figure 1 Immunohistochemical localisation of matrix metalloproteinases (MMP)-2 (A), MMP-3 (B), and MMP-9 (C) in sections of paraffin embedded histologically normal colon. Sections were stained with haematoxylin. MMP-2 staining was observed in subepithelial and pericryptic fibroblasts/ myofibroblasts (open arrow), lamina propria mononuclear cells (arrow), as well as in lamina muscularis mucosa and in vascular endothelial cells. MMP-3 and MMP-9 staining was observed only in a few lamina propria mononuclear cells (arrow) (B, C). Magnification $\times 40$. 

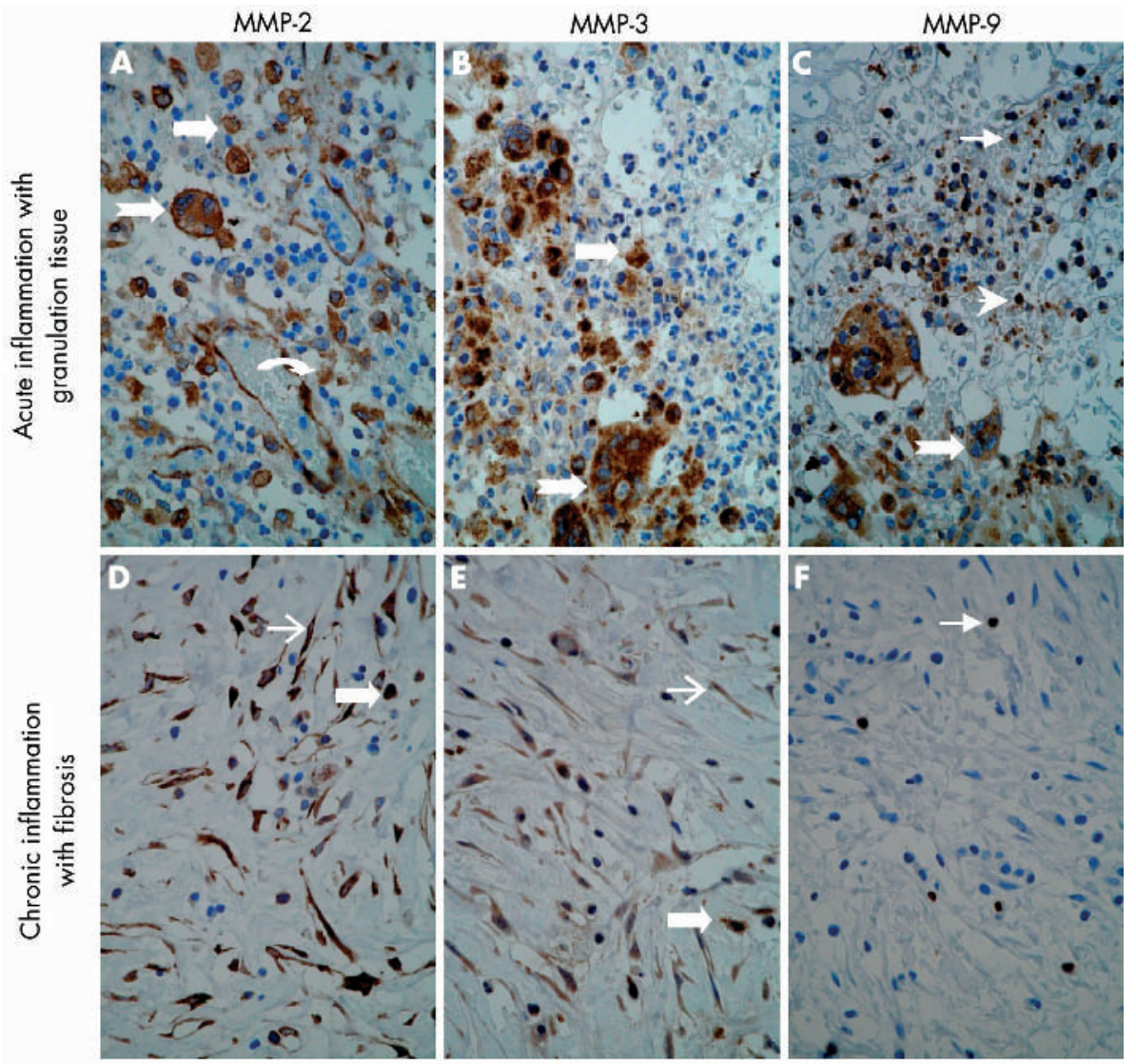

$\rightarrow$ Endothelial cells
$\rightarrow$ Large mononuclear macrophage-like cells
$\rightarrow$ Siant cells
$\rightarrow$ Small mononuclear leucocytes
$\rightarrow$ Fibroblasts

Figure 2 Immunohistochemical localisation of matrix metalloproteinases (MMPs) in a representative Crohn's disease fistula. Sections of paraffin embedded fistula specimens with acute inflammation and granulation tissue $(A-C)$ or chronic inflammation with fibrosis (D-F) were stained with antiMMP-2 (A, D), anti-MMP-3 (B, E), and anti-MMP-9 (C, F). In acute inflammation with granulation tissue, MMP-2 staining was seen in endothelial cells, large mononuclear macrophage-like cells, and giant cells (A). MMP-3 staining was seen in large mononuclear macrophage-like cells and in giant cells (B) while MMP-9 staining was seen in small mononuclear leucocytes, granulocytes, and in giant cells (C). In chronic inflammation with fibrosis, MMP-2 and MMP-3 staining was seen in large mononuclear macrophage-like cells and fibroblasts (D, E) while MMP-9 staining was only observed in sporadic small mononuclear leucocytes and granulocytes (F). Magnification $\times 40$.

unspecific binding, sections were acetylated for 10 minutes in triethanolamine $(0.1 \mathrm{M})$ containing $0.25 \%$ acetic anhydride. Hybridisation was performed in a buffer containing $50 \%$ formamide, $0.3 \mathrm{M} \mathrm{NaCl}, 20 \mathrm{mM}$ Tris/HCl, $\mathrm{pH} 7.5,1 \mathrm{mM}$ EDTA, $1 \times$ Denhardt's, $10 \%$ dextran sulphate, $250 \mu \mathrm{g} / \mathrm{ml}$ tRNA, and ${ }^{33} \mathrm{P}$ labelled antisense or sense RNA probe $\left(5 \times 10^{4}\right.$ $\mathrm{cpm} / \mu \mathrm{l})$. Hybridisation buffer $(100 \mu \mathrm{l})$ was added to each section and hybridisation performed for $16-20$ hours at $55^{\circ} \mathrm{C}$ in a humidified chamber. After hybridisation, sections were washed under stringent conditions, including treatment with RNase A $(20 \mu \mathrm{g} / \mathrm{ml}$; Roche) to remove unbound probe. Finally, sections were passed through graded ethanol containing $0.3 \mathrm{M}$ ammonium acetate, air dried, and dipped in LM- 1 emulsion (Amersham Biosciences). After 28 days exposure at $4{ }^{\circ} \mathrm{C}$ in a light tight box, hybridisation was developed using Kodak phenisol developing reagents according to the manufacturer's instructions. Slides were counterstained with haematoxylin and eosin, and data analysed by observation under a light field photomicroscope. Positive mRNA expression was noted when the cellular grain density was above background levels.

\section{Gelatin zymography analysis}

Tissue extraction was performed as described previously. ${ }^{27}$ In brief, tissue was shaken in 20 volumes of a buffer containing $1 \mathrm{mM}$ cacodylate $\mathrm{HCl}, \mathrm{pH} 6.0,1 \mathrm{M} \mathrm{NaCl}, 0.01 \%$ (v/v) Triton X-100, $1 \mu \mathrm{M} \quad \mathrm{ZnCl}_{2}, 0.2 \mathrm{mg} / \mathrm{ml} \mathrm{NaN}_{3}$ and proteinase inhibitors ( $\mathrm{NaF}(5 \mathrm{mM})$, sodium orthovanadate $(1 \mathrm{mM}))$, and a protease inhibitor cocktail tablet (Roche) for 18 hours at $4^{\circ} \mathrm{C}$. Tissue extracts were centrifuged for five minutes at $5000 \mathrm{rpm}$ and the supernatant was kept at $4^{\circ} \mathrm{C}$ until analysed. Freezing of extracts was not performed to avoid activation of MMPs. To detect the latent and active forms of the gelatinases, MMP-2, and MMP-9, tissue extract 

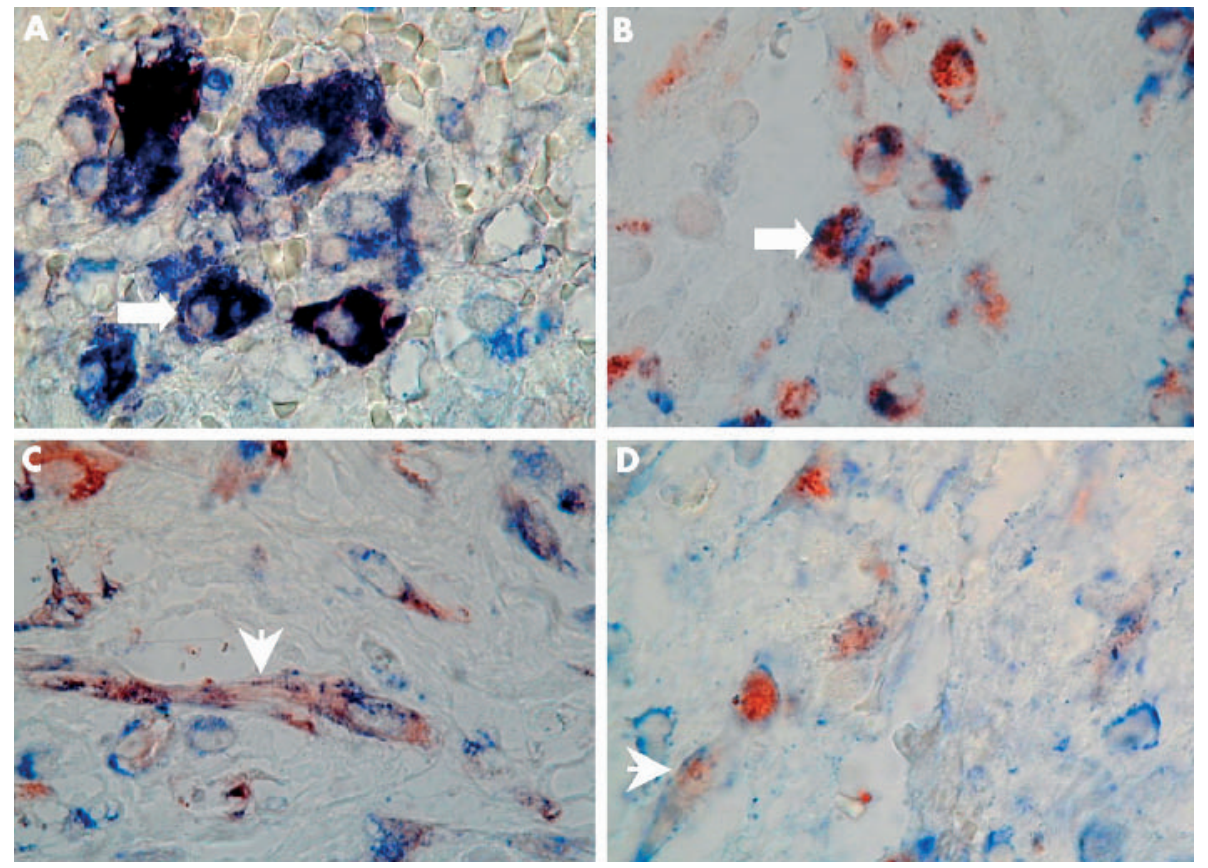

Figure 3 Double immunohistochemical localisation of matrix metalloproteinase MMP-2/MMP-3 and cellular markers for macrophages (CD68) or fibroblasts (vimentin) in a representative Crohn's disease fistula. Double immunostaining was performed as described in materials and methods. The chromogen reactions were developed with 3-amino-9-ethylcarbazole for MMPs (red colour) and Fast Blue BB for cellular markers (blue colour). Dark brown to black reaction representing concomitant staining of MMP-2 and CD68 in large mononuclear macrophage-like cells (arrow) (A). Colocalisation of MMP-3 and CD68 in large mononuclear macrophage-like cells, represented by concomitant red and blue cytoplasmic granules (arrow) (B). Colocalisation of MMP-2 (C) or MMP-3 (D) and vimentin in fibroblasts, represented by concomitant red and blue cytoplasmic granules (arrowheads). Magnification $\times 100$.

(7.5 $\mu \mathrm{g}$ total protein) was separated by electrophoresis on a $10 \%$ zymogram gel with $0.1 \%$ gelatin as substrate. A mixed

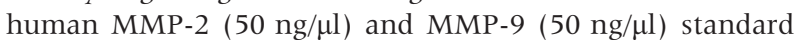
(Chemicon International, California, USA) was used as a positive control. The gels were washed three times in $2.5 \%$ Triton X-100 and incubated in a buffer containing $5 \mathrm{mM}$ $\mathrm{CaCl}_{2}, 1 \mu \mathrm{M} \mathrm{ZnCl}_{2}, 50 \mathrm{mM}$ Tris $\mathrm{HCl}, \mathrm{pH} 7.4,0.1 \%$ Triton X100 , and $0.003 \mathrm{M} \mathrm{NaN}_{3}$ for 18 hours at $37^{\circ} \mathrm{C}$ with continuous shaking. Zymograms were stained in $0.25 \%$ Coomassie Brilliant Blue R-250, 10\% acetic acid, and 45\% methanol for 30 minutes and destained in $20 \%$ acetic acid, $20 \%$ methanol, $17 \%$ ethanol, and $0.6 \%$ diethylether (30 minutes; fast destain) and in 20\% acetic acid (1-3 hours; slow destain). Zymograms were preserved in $3 \%$ glycerol, dried, and scanned.

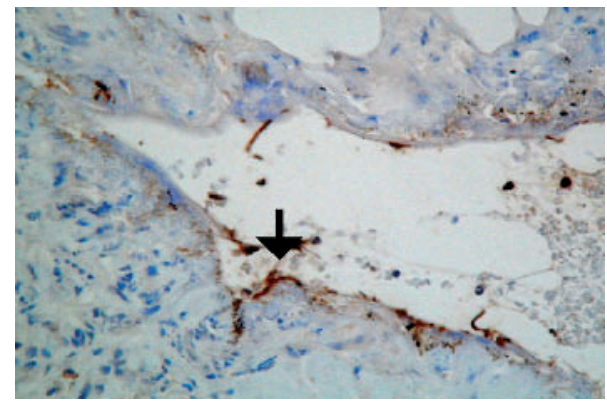

Figure 4 Immunohistochemical localisation of matrix metalloproteinase (MMP)-3 in a Crohn's disease fistula. Sections of a paraffin embedded fistula sample with an intact fistula tract were stained with anti-MMP-3. Strong immunostaining was observed in mononuclear macrophage-like cells facing towards the fistula lumen, as well as within the lumen (arrow).

\section{Statistics}

One way analysis of variance (ANOVA) followed by Bonferroni's multiple comparison test was used. Two tailed $p$ values $<0.05$ were considered significant.

\section{RESULTS}

MMP and TIMP protein expression in normal colon

Cellular distribution of MMP-1, MMP-2, MMP-3, MMP-7, MMP-9, MMP-10, TIMP-1, TIMP-2, and TIMP-3 protein expression was first investigated in normal colon. Abundant MMP-2 staining was observed in subepithelial and pericryptal fibroblast/myofibroblast sheaths, in lamina propria mononuclear cells (macrophages and lymphocytes), and in vascular endothelial cells (fig lA). MMP-2 staining was also seen in the lamina muscularis mucosa. In contrast, positive staining for MMP-3 and MMP-9 was observed in only a few lamina propria mononuclear cells (fig 1B, C). Neither MMP-1 nor MMP-7 was expressed in normal colon (data not shown), and MMP-10 was observed only in the colonic epithelium (data not shown). TIMP-1 protein expression was observed only in a few lamina propria mononuclear cells whereas TIMP-2 and TIMP-3 staining was observed in the colonic epithelium as well as in a few lamina propria mononuclear cells (data not shown).

MMP and TIMP protein expression in fistula specimens In common with the normal colon, abundant MMP-2 staining was also observed in fistulae of patients with Crohn's disease. In specimens with acute inflammation and granulation tissue, MMP-2 staining was seen in large mononuclear macrophage-like cells, in giant cells, and in endothelial cells ( fig 2A). In samples with chronic inflammation and fibrosis, MMP-2 staining was localised in fibroblasts and in large mononuclear macrophage-like cells (fig 2D). Strong immunostaining for MMP-3 was observed in both 


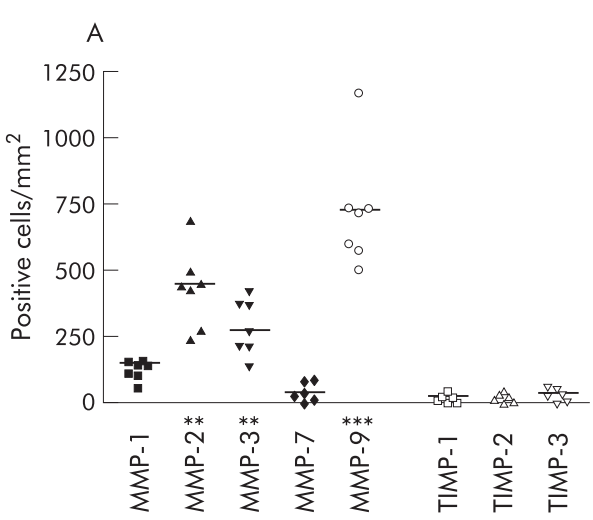

Acute inflammation with granulation tissue
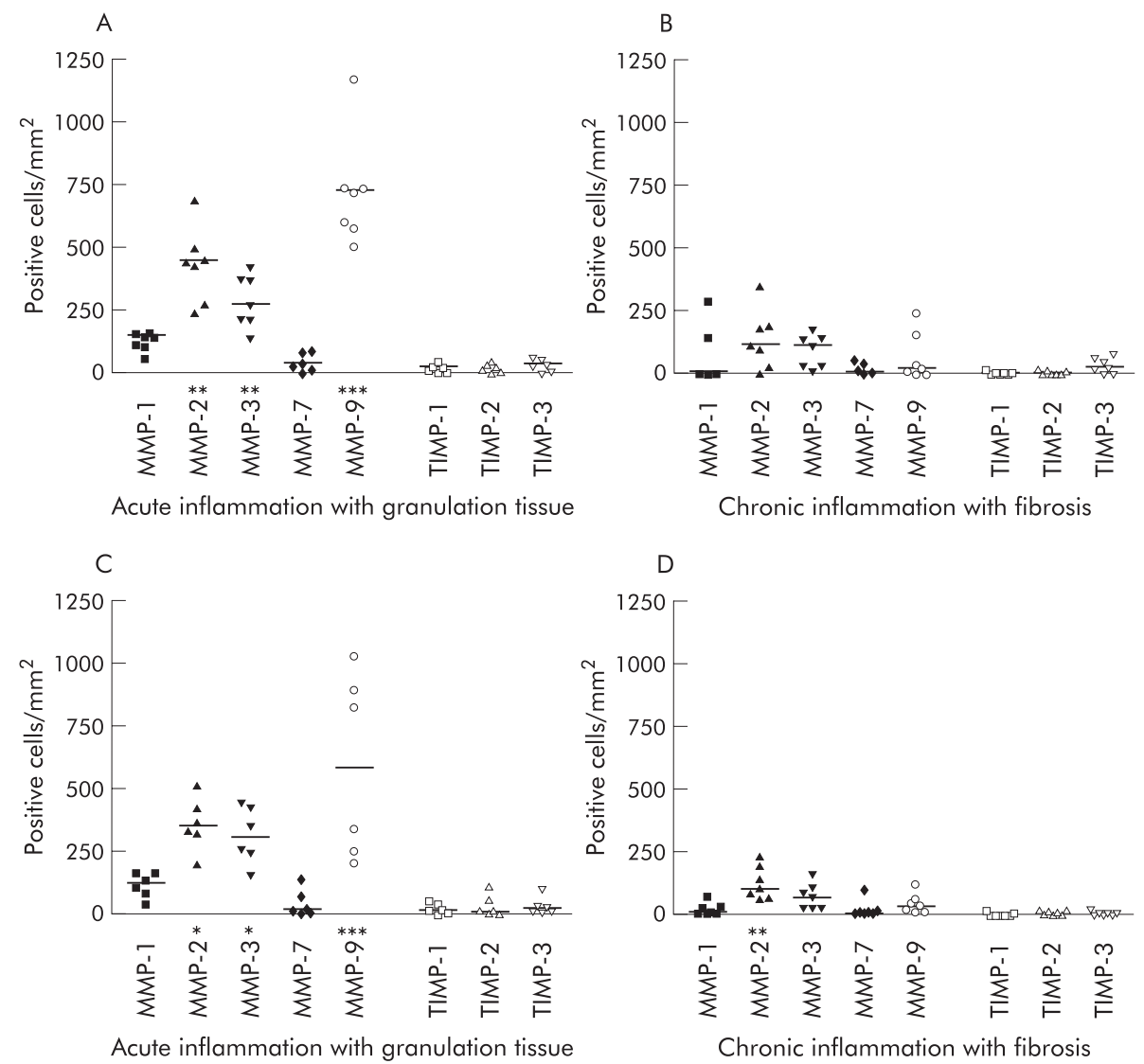

Figure 5 Quantification of matrix metalloproteinase (MMP) and tissue inhibitor of metalloproteinase (TIMP) protein expression in fistula specimens divided according to the predominant stage of inflammatory activity. Four fistula specimens with acute inflammation and granulation, four specimens with chronic inflammation and fibrosis, and three specimens with a combination were included from patients with Crohn's disease $(n=11)(A, B)$. Two fistula specimens with acute inflammation with granulation tissue, three specimens with chronic inflammation with fibrosis, and four specimens with both were included from patients without Crohn's disease $(n=9)(C, D)$. Horizontal lines indicate median values. ${ }^{*} p<0.05$ versus $M M P-7$; ${ }^{* *} p<0.01$ versus MMP-1, MMP-7, or both; ${ }^{* * *} \mathrm{p}<0.001$ versus MMP-1 and MMP-7.

types of fistulae compared with normal colon. In specimens with acute inflammation, MMP-3 staining was observed in large mononuclear macrophage-like cells and in giant cells (fig 2B). In specimens with chronic inflammation and fibrosis, MMP-3 staining was seen in large mononuclear macrophage-like cells and in fibroblasts (fig 2E). Abundant MMP-9 staining was observed in small mononuclear leucocytes, in granulocytes, and in giant cells in specimens with acute inflammation with granulation tissue (fig 2C). Only a few scattered small mononuclear leucocytes and granulocytes stained positive for MMP-9 in specimens with chronic inflammation and fibrosis (fig 2F). Staining for MMP-1 and MMP-7 was weak in all samples and completely negative for MMP-10, probably reflecting the lack of intact epithelial linings (data not shown). Cellular localisation of MMP-2 and MMP-3 was confirmed by double immunohistochemical staining for MMP-2 or MMP-3 combined with cellular markers for macrophages (CD68) and fibroblasts (vimentin) (fig 3). Similar to normal colon, positive TIMP-1, TIMP-2, and TIMP-3 staining was observed only in sporadic large mononuclear macrophage-like cells in both types of fistulae (data not shown).

To further illustrate the role of MMPs in tissue degradation during fistula formation, localisation of MMP-2, MMP-3, and MMP-9 protein was also examined in an occasionally available longitudinal section of an intact fistula tract. Figure 4 shows a representative section with prominent MMP-3 protein staining in mononuclear macrophage-like cells facing towards the fistula lumen with minimal staining in the surrounding non-inflamed tissue. Moreover, extracellular MMP-3 staining within the fistula lumen was observed.

Finally, when fistula specimens obtained from a heterogeneous group of patients without Crohn's disease (table 2) were stratified according to the stage of inflammation as above, a very similar cellular pattern of MMP and TIMP staining was observed (data not shown).

\section{Quantification of MMP and TIMP protein expression in fistula specimens}

To quantify the relative expression of individual MMPs and TIMPs in the entire patient material, the number of positive cells $/ \mathrm{mm}^{2}$ were counted in each fistula specimen. Due to the structural differences in tissue architecture, a direct comparison with normal colon based on cell numbers was not feasible. Staining for MMP-10 protein was invariably negative in all samples and therefore omitted from the figure. In Crohn's disease fistulae with acute inflammation and granulation tissue, the median number of MMP-2, MMP-3, and MMP-9 positive cells was significantly (2-20-fold) higher than those for MMP-1, MMP-7, or both (fig 5A). Total cell numbers were lower in samples with chronic inflammation and fibrosis, and even though the median number of MMP-2 and MMP-3 positive cells was also markedly higher than those for MMP-1 and MMP-7, statistical significance was not reached (fig 5A, B). Likewise, no significant increase in the number of MMP-9 

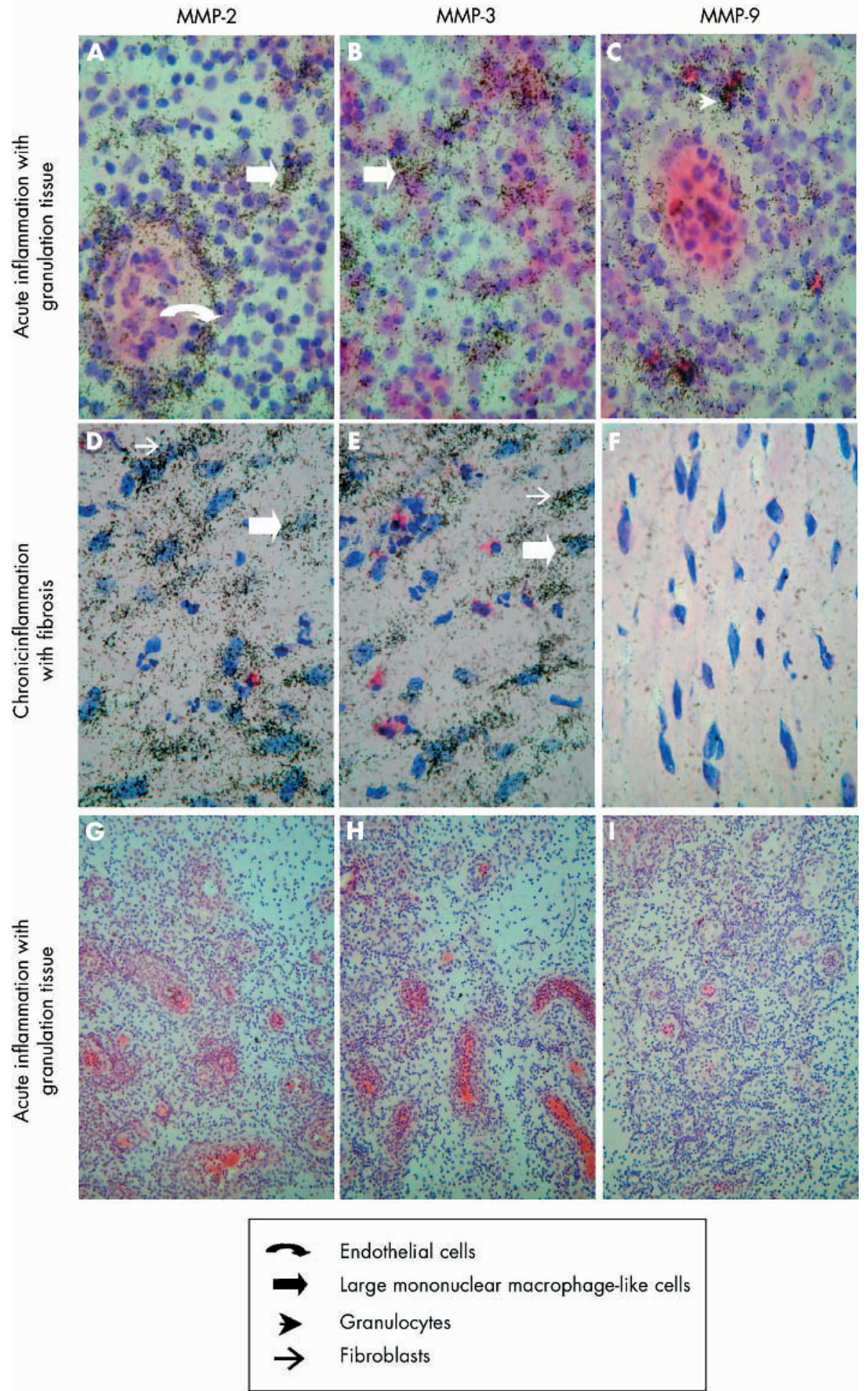

Figure 6 In situ hybridisation of matrix metalloproteinase (MMP) mRNA expression in a Crohn's disease fistula. Sections of a paraffin embedded fistula specimen with acute inflammation and granulation tissue (A-C, G-I) and chronic inflammation with fibrosis (D-F) were hybridised with antisense MMP-2 (A, D), MMP-3 (B, E), and MMP-9 (C, F) or sense MMP-2 (G), MMP-3 (H), and MMP-9 (I). In acute inflammation with granulation tissue, MMP-2 mRNA expression was observed in large mononuclear macrophage-like cells and endothelial cells (A). MMP-3 mRNA expression was seen in large mononuclear macrophages-like cells (B) while MMP-9 mRNA expression was seen in granulocytes and small mononuclear leucocytes (data not shown) (C). In chronic inflammation with fibrosis, MMP-2 and MMP-3 was seen in large mononuclear macrophage-like cells and in fibroblasts (D, E) while MMP-9 was seen in sporadic small mononuclear leucocytes and granulocytes (data not shown). Magnification $\times 100(A-F)$ and $\times 20(G-1)$.

positive cells was observed in these specimens. The median numbers of TIMP-1, TIMP-2, and TIMP-3 positive cells were very low in both types of specimens examined, and no significant differences were observed (fig 5A, B). As shown in fig 5C and 5D, very similar MMP and TIMP expression profiles were observed when the number of positive cells was quantified in fistulae of patients from the disease control group. 


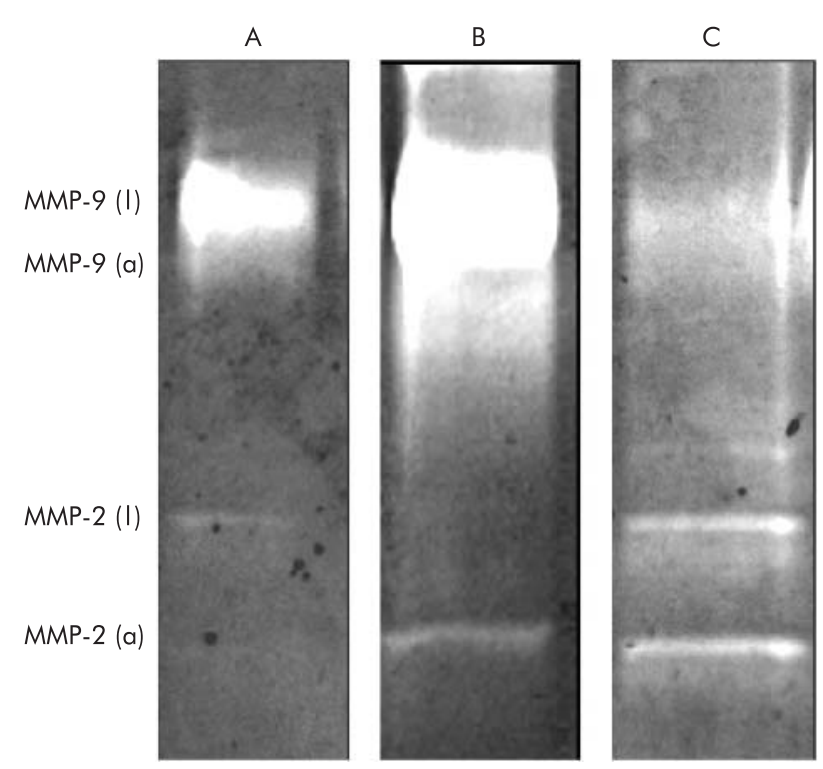

Figure 7 Representative gelatin zymographs showing the presence of the latent (I) and active (a) forms of matrix metalloproteinase (MMP)-2 and MMP-9 (gelatinises) in normal colon (A) and in fistula specimens of patients with Crohn's disease (B, C).

Expression of MMP mRNA in Crohn's disease fistulae To extend the key findings in the immunohistochemical studies, cellular localisation of MMP-2, MMP-3, and MMP-9 mRNA was examined by in situ hybridisation using ${ }^{33} \mathrm{P}$ labelled RNA probes. Figure 6 shows representative mRNA expression studies in fistula sections of a patient with Crohn's disease. In specimens with acute inflammation and granulation tissue, MMP-2 mRNA expression was observed in endothelial cells and in large mononuclear macrophagelike cells (fig 6A). In those with chronic inflammation and fibrosis, MMP-2 mRNA expression was observed in large mononuclear macrophage-like cells and in fibroblasts (fig 6D). MMP-3 mRNA expression was only detected in large mononuclear macrophage-like cells in fistulae with acute inflammation and granulation tissue (fig 6B). In samples with chronic inflammation and fibrosis, MMP-3 mRNA expression was observed in large mononuclear macrophage-like cells as well as in fibroblasts (fig 6E). Finally, abundant MMP-9 mRNA expression was observed in granulocytes (fig 6C) and sporadically in a few small mononuclear leucocytes in fistula samples with acute inflammation and granulation tissue. With the exception of a few small mononuclear leucocytes and granulocytes, MMP-9 mRNA was, as expected, not detected in samples with chronic inflammation and fibrosis (fig 6F). No signals were detected in samples hybridised with sense MMP-2, MMP-3, and MMP-9 RNA probes (fig 6G-I). A very similar cellular pattern of MMP mRNA expression was observed when specimens obtained from a heterogeneous group of patients without Crohn's disease (table 2) were examined and stratified according to the stage of inflammation as above (data not shown). In summary, cellular localisation of MMP-2, MMP-3, and MMP-9 mRNA was in good agreement with immunohistochemical findings, except that MMP mRNA was not expressed in giant cells.

\section{Enzyme analysis of tissue extracts}

To extend the key findings in the morphological studies, we examined whether fistula specimens express MMP activity, as measured by gelatin zymography. As shown in fig 7, increased gelatinolytic activity corresponding to the active form of MMP-2 was observed in fistula specimens of patients with Crohn's disease. Likewise, the latent and active forms of MMP-9 were identified, reflecting the stage of inflammatory activity.

\section{DISCUSSION}

Using immunohistochemical analysis, we have shown that MMP-2 and MMP-3 protein is consistently expressed in fistulae of patients with Crohn's disease, irrespective of the stage of inflammatory activity. MMP-9 protein was also abundantly expressed in these specimens but only in those with prominent acute inflammation. In contrast, MMP-1, MMP-7, and MMP-10, as well as TIMP-1, TIMP-2, and TIMP-3 protein staining was either absent or only barely detectable. These findings were supported by in situ hybridisation showing very similar expression patterns for MMP-2, MMP-3, and MMP-9 mRNA, which suggest that these proteinases are also actively synthesised during fistula formation. The patterns of MMP and TIMP expression were not unique to Crohn's disease as similar profiles were observed in specimens of patients with fistulae due to other diseases.

MMP-2 (gelatinase A) cleaves gelatin, type V, VII, and X collagens, as well as basement membrane type IV collagen ${ }^{28}$ and has therefore been implicated in tumour cell invasion. ${ }^{11}$ 29-32 Using gelatin zymography, increased MMP-2 activity has previously been demonstrated in Crohn's disease but the cellular sources have not been clearly identified. ${ }^{12}$ In our specimens, MMP-2 was expressed not only in endothelial cells and inflammatory cells but also in fibroblasts. This accords with findings in colonic fibroblast cultures ${ }^{1321}$ and certain invasive tumours, ${ }^{31-33}$ and emphasises the importance of stromal cells as local producers of MMPs in inflamed gut. ${ }^{13}$ Unlike the other MMPs examined, MMP-2 was also abundantly expressed in normal colon, raising the question of whether MMP-2 truly plays a pathogenic role in fistula formation. MMP-2 exists in a latent $66 \mathrm{kDa}$ form expressed in normal colon and in an active $60 \mathrm{kDa}$ form which is mainly expressed in inflamed mucosa. ${ }^{12}$ Increased proteolytic activity of MMP-2 is also present in Crohn's disease fistulae and our data suggest that the active form may contribute to fistula formation through degradation of the basement membrane which forms a network supporting endothelial and epithelial cell linings in the gut.

While the exact role of MMP-2 in mucosal injury remains to be fully clarified, our finding of strong MMP-3 expression in large mononuclear cells and fibroblasts accords with previous studies in luminal Crohn's disease, ${ }^{15-17} 19$ except one. ${ }^{12}$ The same applies to the minimal staining for MMP-3 in normal colon. MMP-3 (stromelysin-1) cleaves proteoglycans, collagens (type II, IX, XI), gelatin, laminin, and fibronectin, ${ }^{33}$ and has been linked to tissue degradation in rheumatoid arthritis ${ }^{35}$ and in certain human cancers. ${ }^{11} 34$ Likewise, functional experiments in an ex vivo human fetal small intestine explant model have clearly shown that MMP3 also acts as a key mediator of T cell and TNF- $\alpha$ mediated tissue injury in the gut. ${ }^{21}{ }^{36}{ }^{37}$ Our data extend these findings by suggesting that increased release of MMP-3 also may contribute to fistula formation by degrading the matrix in areas with active inflammation. Moreover, our data on TIMP expression are consistent with previous findings in children with IBD showing marked upregulation of MMP-3 in inflamed mucosa without a parallel increase in expression of its natural inhibitor (that is, TIMP-1). ${ }^{17}$

The substrate specificity of MMP-9 (gelatinase B) is similar to MMP-2, and MMP-9 has also been implicated in cancer cell invasion. ${ }^{38}$ Only minimal staining for MMP-9 expression was observed in normal colon, ${ }^{12}{ }^{18}$ and MMP-9 was virtually absent in fistulae with chronic inflammation and prominent 
fibrosis, which accords with previous findings in myofibroblast cultures. ${ }^{21}$ In contrast, strong MMP-9 expression was consistently detected in leucocytes, most notably granulocytes, in specimens with prominent acute inflammation. This is consistent with previous findings in Crohn's disease mucosa ${ }^{18}$ as well as in homogenates of purified neutrophils. ${ }^{13}$ Strong MMP-9 activity has previously been demonstrated in colonic mucosa with active Crohn's disease using gelatin zymography. ${ }^{12}$ A similar increase was noted in fistula specimens, which suggest that MMP-9 may contribute to fistula formation through a mechanism similar to that of MMP-2. Moreover, MMP-9 may contribute to tissue injury by promoting extravasation of neutrophils in areas with acute inflammation ${ }^{18}$ as well as by accelerating proteolysis of matrix proteins partly degraded by other MMPs. ${ }^{18}$

In conclusion, we have shown that MMP-3 and MMP-9 are strongly expressed in fistula specimens of patients with or without Crohn's disease compared with normal colon. As TNF- $\alpha$ blockade improves the clinical course of fistulising Crohn's disease, ${ }^{2}$ probably though inhibition of MMP-3 activity, $^{22}$ specific MMP inhibitors ${ }^{39}$ that also target the TNF- $\alpha$ converting enzyme may in theory provide additional therapeutic benefit for these patients. ${ }^{40}$

\section{ACKNOWLEDGEMENTS}

Tove Kirkegaard is the recipient of an Industrial PhD grant from the Danish Academy of Technical Science (ATV). The technical assistance of Hanne Fuglsang, Anne Hallander, Birgit Dejbjerg, Anni Petersen, and Vibeke Voxen at Laboratory of Gastroenterology 54O3, Herlev University Hospital, Denmark, and of Ulla Gundø and the technician staff at Department of Pathology, Herlev University Hospital, Denmark, are greatly appreciated.

\section{Authors' affiliations}

T Kirkegaard, J Brynskov, Department of Medical Gastroenterology C, Herlev Hospital, University of Copenhagen, Denmark

A Hansen, Department of Pathology, Herlev Hospital, University of Copenhagen, Denmark

E Bruun, Department of Surgical Gastroenterology D, Herlev Hospital, University of Copenhagen, Denmark

\section{REFERENCES}

1 Schwartz D, Loftus E, Tremaine W, et al. The natural history of fistulizing Crohn's disease: a population based study. Gastroenterology 2002; 122:875-80.

2 Present DH, Rutgeerts P, Targan S, et al. Infliximab for the treatment of fistulas in patients with Crohn's disease. N Engl J Med 1999;340:1398-405.

3 Arseneau KO, Cohn SM, Cominelli F, et al. Cost-utility of initial medical management for Crohn's disease perianal fistulae. Gastroenterology 2002; 120:1640-56

4 Falconi M, Pederzoli P. The relevance of gastrointestinal fistulae in clinical practice: a review. Gut 2002;49(suppl IV):iv2-10.

5 Levy C, Tremaine WJ. Management of internal fistulae in Crohn's disease. Inflamm Bowel Dis 2002;8:106-11.

6 Podolsky DK. Inflammatory bowel disease. N Engl J Med 2002;347:417-25.

7 Abreu MT, Taylor KD, Lin YC, et al. Mutations in NOD2 are associated with fibrostenosing disease in patients with Crohn's disease. Gastroenterology 2002; 123:679-88.

8 Gasché C, Schölmerich J, Brynskov J, et al. A simple classification of Crohn's disease: Report of the Working Party for the World Congress of Gastroenterology, Vienna. Inflamm Bowel Dis 2000;6:8-15.

9 Murphy G. Matrix metalloproteinases and their inhibitors. Acta Orthop Scand Suppl 1995;266:55-60.

10 Matrisian LM. Metalloproteinases and their inhibitors in matrix remodeling. Trends Genet 1990;6:121-5

11 Nelson AR, Fingleton B, Rothenberg ML, et al. Matrix metalloproteinases: biologic activity and clinical implications. J Clin Oncol 2000;18:1135-49.

12 Baugh MD, Perry MJ, Hollander AP, et al. Matrix metalloproteinase levels are elevated in inflammatory bowel disease. Gastroenterology $1999 ; 117: 814-22$.
13 Baugh MD, Evans GS, Hollander AP, et al. Expression of matrix metalloproteases in inflammatory bowel disease. Ann N Y Acad Sci 1998;859:249-53.

14 Arihiro S, Ohtani $\mathrm{H}$, Hiwatashi $\mathrm{N}$, et al. Vascular smooth muscle cells and pericytes express MMP-1, MMP-9, TIMP-1 and type I procollagen in inflammatory bowel disease. Histopathology 2001;39:50-9.

15 von Lampe B, Barthel B, Coupland SE, et al. Differential expression of matrix metalloproteinases and their tissue inhibitors in colon mucosa of patients with inflammatory bowel disease. Gut 2000:47:63-73.

16 Louis E, Ribbens C, Godon A, et al. Increased production of matrix metalloproteinase- 3 and tissue inhibitor of metalloproteinase- 1 by inflamed mucosa in inflammatory bowel disease. Clin Exp Immunol 2000; 120:241-6.

17 Heuschkel RB, MacDonald T, Monteleone G, et al. Imbalance of stromelysin and TIMP-1 in the mucosal lesions of children with inflammatory bowel disease. Gut 2000;47:57-62.

18 Bailey CJ, Hembry RM, Alaxander A, et al. Distribution of the matrix metalloproteinases stromelysin, gelatinases $A$ and $B$, and collagenase in Crohn's disease and normal intestine. J Clin Pathol 1994:47:113-16.

19 Saarialho-Kere UK, Vaalamo M, Puolakkainen $\mathrm{P}$, et al. Enhanced expression of matrilysin, collagenase, and stromelysin-1 in gastrointestinal ulcers. Am J Pathol 1996;148:519-26.

20 Vaalamo M, Karjalainen-Lindsberg ML, Puolakkainen P, et al. Distinct expression profiles of stromelysin-2 (MMP-10), collagenase-3 (MMP-13), macrophage metalloelastase (MMP-12), and tissue inhibitor of metalloproteinases-3 (TIMP-3) in intestinal ulcerations. Am J Pathol 1998; 152:1005-14.

21 Pender SLF, Tickle SP, Docherty AJP, et al. A major role for matrix metalloproteinases in T cell injury in the gut. J Immunol 1997;158:1582-90.

22 Munkholm P, Langholz E, Nielsen $\mathrm{OH}$, et al. Incidence and prevalence of Crohn's disease in the county of Copenhagen, 1962-87: a sixfold increase in incidence. Scand J Gastroenterol 1992;27:609-14.

23 Cotan RS, Kumar V Collins TC. Acute and chronic inflammation. In: Cotan RS Kumar V, Collins T, eds. Robins-Pathologic basis of disease. Philadelphia: WB Saunders, 1999:50-88.

24 Wright NA. The response to injury. In: McGee JO, Isaacson PG, Wright NA, eds. Oxford textbook of pathology. Oxford: Oxford University Press, 1992:349-406.

25 Vergara E, Gómez-Morales M, Osuna A, et al. Immunohistochemical quantification of leukocyte subsets in the long-term prognosis of kidney transplants. Transplant Proc 1998;30:2380-3.

26 Holm-Bentzen M, Jacobsen F, Nerstrøm B, et al. A prospective double-blind clinically controlled multicenter trial of sodium pentosanpolysulfate in the treatment of interstitial cystitis and related painful bladder disease. J Urol 1987; 138:503-7

27 Mirastschijski U, Impola U, Karsdal MA, et al. Matrix metalloproteinase inhibitor BB-3103 unlike the serine proteinase inhibitor aprotinin abrogates epidermal healing of human skin wounds ex vivo. J Invest Dermatol 2002; 118:55-64.

28 Collier IE, Wilhelm SM, Eisen AZ, et al. H-ras oncogene-transformed human bronchial epithelial cells (TBE-1) secrete a single metalloprotease capable of degrading basement membrane collagen. J Biol Chem 1988;263:6579-87.

29 Kikuchi R, Noguchi T, Takeno S, et al. Immunohistochemical detection of membrane-type-1-matrix metalloproteinase in colorectal carcinoma. Br J Cancer 2000;83:215-18.

30 Poulsom R, Pignatelli M, Stetler-Stevenson WG et al. Stromal expression of 72 kda type IV collagenase (MMP-2) and TIMP-2 mRNAs in colorectal neoplasmia. Am J Pathol 1992;141:389-96.

31 Tryggvason K, Höyhtä M, Pyke M. Type IV collagenases in invasive tumors. Breast Cancer Res Treat 1993;24:209-18.

32 Pyke C, Ralfkiaer E, Tryggvason K, et al. Messenger RNA for two type IV collagenases is located in stromal cells in human colon cancer. Am J Pathol 1993; 142:359-65.

33 Murphy G, Cockett MI, Ward RV, et al. Matrix metalloproteinase degradation of elastin, type IV collagen and proteoglycan. A quantitative comparison of the activities of $95 \mathrm{kDa}$ and $72 \mathrm{kDa}$ gelatinases, stromelysins- 1 and -2 and punctuated metalloproteinase (PUMP). Biochem J 1991;277:277-9.

34 Basset $\mathrm{P}$, Bellocq JP, Wolf C, et al. A novel metalloproteinase gene specifically expressed in stromal cells of breast carcinomas. Nature 1990:348:699-704.

35 Hasty KA, Reife RA, Kang AH, et al. The role of stromelysin in the cartilage destruction that accompanies inflammatory arthritis. Arthritis Rheum 1990;33:388-97.

36 Pender SLF, Fell JME, Chamow SM, et al. A p55 TNF receptor immunoadhesin prevents $T$ cell-mediated intestinal injury by inhibiting matrix metalloproteinase production. J Immunol 1998;160:4098-103

37 Salmela MT, MacDonald TT, Black D, et al. Upregulation of matrix metalloproteinases in a model of T cell mediated tissue injury in the gut: analysis by gene array and in situ hybridization. Gut 2002;51:540-7.

$38 \mathrm{Kim} \mathrm{J}, \mathrm{Yu}$ W, Kovalski K, et al. Requirement for specific proteases in cancer cell intravasation as revealed by a novel semiquantitative PCR-based assay. Cell 1998;94:353-62.

39 Brinckerhoff CE, Matrisian LM. Matrix metalloproteinases: a tail of a frog that became a prince. Nat Rev Mol Cell Biol 2002;3:207-14

40 Brynskov J, Foegh P, Pedersen G, et al. Tumour necrosis factor $\alpha$ converting enzyme (TACE) activity in the colonic mucosa of patients with inflammatory bowel disease. Gut 2002;51:37-43. 